\title{
Mutation of $\beta$-glucosidase 2 causes glycolipid storage disease and impaired male fertility
}

\author{
Yildiz Yildiz, ${ }^{1}$ Heidrun Matern, ${ }^{2}$ Bonne Thompson, ${ }^{1}$ Jeremy C. Allegood, ${ }^{3}$ \\ Rebekkah L. Warren, ${ }^{1}$ Denise M.O. Ramirez, ${ }^{1}$ Robert E. Hammer, ${ }^{4}$ \\ F. Kent Hamra, ${ }^{5}$ Siegfried Matern, ${ }^{2}$ and David W. Russell ${ }^{1}$
}

\begin{abstract}
1Department of Molecular Genetics, University of Texas Southwestern Medical Center, Dallas, Texas, USA. ²Department of Internal Medicine III, Rheinisch-Westfälische Technische Hochschule Aachen, Aachen, Germany. ${ }^{3}$ School of Biology, Georgia Institute of Technology, Atlanta, Georgia, USA ${ }^{4}$ Department of Biochemistry and 5Department of Pharmacology, University of Texas Southwestern Medical Center, Dallas, Texas, USA.
\end{abstract}

\begin{abstract}
$\beta$-Glucosidase 2 (GBA2) is a resident enzyme of the endoplasmic reticulum thought to play a role in the metabolism of bile acid-glucose conjugates. To gain insight into the biological function of this enzyme and its substrates, we generated mice deficient in GBA2 and found that these animals had normal bile acid metabolism. Knockout males exhibited impaired fertility. Microscopic examination of sperm revealed large round heads (globozoospermia), abnormal acrosomes, and defective mobility. Glycolipids, identified as glucosylceramides by mass spectrometry, accumulated in the testes, brains, and livers of the knockout mice but did not cause obvious neurological symptoms, organomegaly, or a reduction in lifespan. Recombinant GBA2 hydrolyzed glucosylceramide to glucose and ceramide; the same reaction catalyzed by the $\beta$-glucosidase acid 1 (GBA1) defective in subjects with the Gaucher's form of lysosomal storage disease. We conclude that GBA2 is a glucosylceramidase whose loss causes accumulation of glycolipids and an endoplasmic reticulum storage disease.
\end{abstract}

\section{Introduction}

Glycolipids are an abundant and diverse class of lipids in mammalian cells that play important functional roles in membrane structure and signaling $(1,2)$. A particularly complex class of glycolipids is the glycosphingolipids, which are composed of a sphingosine backbone linked to a fatty acid and 1 or more hexose sugars (3). Recent chemical analyses indicate that a typical mammalian cell may contain as many as 10,000 different glycosphingolipids (www. sphingomap.org). This structural complexity is generated by an equally elaborate network of biosynthetic and degradative enzymes (4), many of which remain to be biochemically identified.

Glycosphingolipids are synthesized in the ER and Golgi compartments of the cell and broken down in lysosomes (5). The functional consequences of this subcellular organization are evident in human genetic diseases in which glycosphingolipid degradation is affected. Loss of any one of a number of catabolic enzymes causes accumulation of glycosphingolipids in the lysosome and a variety of symptoms that worsen with age (6).

The most common inherited defect in glycosphingolipid breakdown is Gaucher's disease, an autosomal-recessive disorder arising from mutations in the gene encoding the lysosomal acid $\beta$-glucosidase acid 1 (GBA1) (7). GBA1 is a membrane-associated enzyme that cleaves the glucose-sphingosine linkage present in glucosylceramides and other glucosphingolipids. The enzyme is abundant in macrophages, which normally degrade large amounts of cellular membrane lipids acquired by phagocytosis. When GBA1 is absent or impaired, glucosphingolipids accumulate within the macrophage lysosome, and the engorged cells in turn are deposited in the liver, spleen, and lung, causing organ enlargement and progressive dysfunction. Current treatments for Gaucher's disease

Nonstandard abbreviations used: DAZL, deleted in Azoospermia-like; GBA1, $\beta$-glucosidase acid 1; GBA2, $\beta$-glucosidase 2.

Conflict of interest: The authors have declared that no conflict of interest exists. Citation for this article: J. Clin. Invest. 116:2985-2994 (2006). doi:10.1172/JCI29224. include enzyme replacement therapy with recombinant GBA1 (Cerezyme; Genzyme Corp.) and substrate-reduction therapy with $N$-butyldeoxynojirimycin (Zavesca; Actelion Pharmaceuticals), which decreases the biosynthesis of glucosylceramides and thereby reduces their accumulation (8).

GBA1 is classified as an $O$-glycosyl hydrolase, a widely distributed group of enzymes that cleave $O$-glycosyl linkages between carbohydrates or between carbohydrates and lipids (9). GBA1 is distinguished from other $O$-glycosyl hydrolases by an acidic $\mathrm{pH}$ optimum and a preference for glycolipids. A second hydrolase with these general properties is $\beta$-glucosidase 2 (GBA2), a membrane-bound enzyme of the ER that is active in both the cleavage and the formation of bile acid glucosides and is inhibited by alkyl-deoxynojirimycin derivatives (10-13). Bile acid glucosides, in which glucose is attached in $\beta$-linkage to carbon 3 of the bile acid (14), are normally excreted in the urine (15). Their synthesis by the liver is thought to assist in the disposal of hepatotoxic bile acids $(16,17)$. Although GBA1 and GBA2 are both glycolipid hydrolases, the 2 enzymes apparently act on different glycolipids, do not share sequence identity, and are expressed in different tissues and subcellular compartments.

To gain insight into the metabolism of bile acid glucosides, we produced a line of knockout mice with a disruption in Gba2. Unexpectedly, bile acid metabolism was normal in the mutant mice, but glucosylceramides were found to accumulate in multiple tissues. Accumulation in the testes led to decreased fertility and the formation of abnormal sperm. These data reveal GBA2 to be a second glucosylceramidase that is located in the ER rather than the lysosome and that plays an important role in preventing glycolipid accumulation.

\section{Results}

Tissue distribution of mouse GBA2. A full-length cDNA encoding the mouse GBA2 enzyme was isolated by RT-PCR from liver mRNA. Conceptual translation of the cDNA sequence predicted a protein of 918 amino acids with $83 \%$ sequence identity to the previously 
A

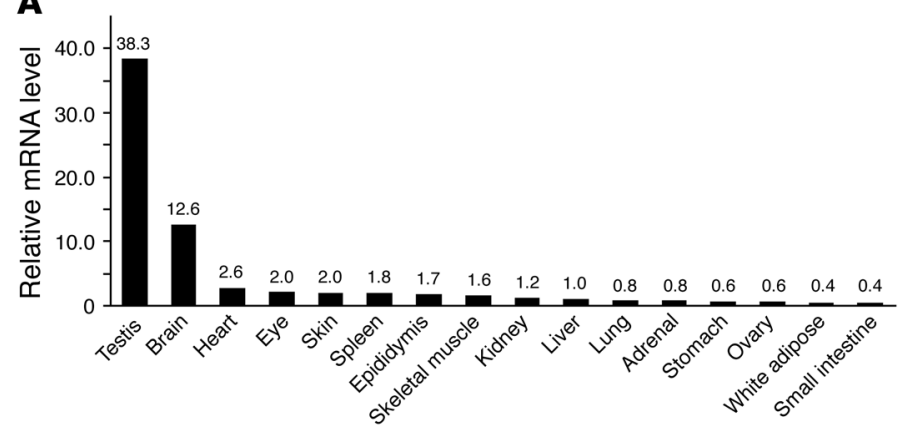

B

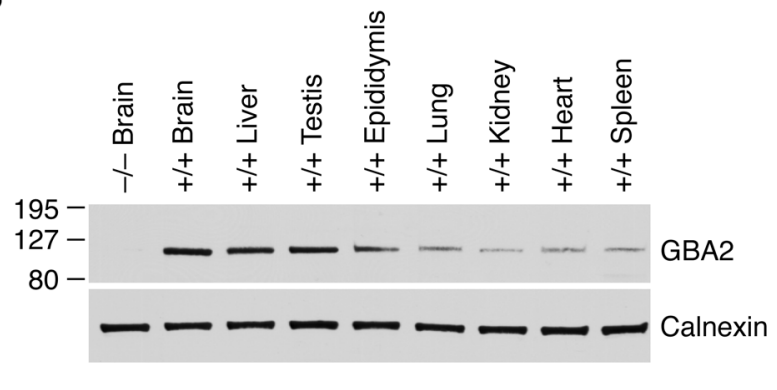

C

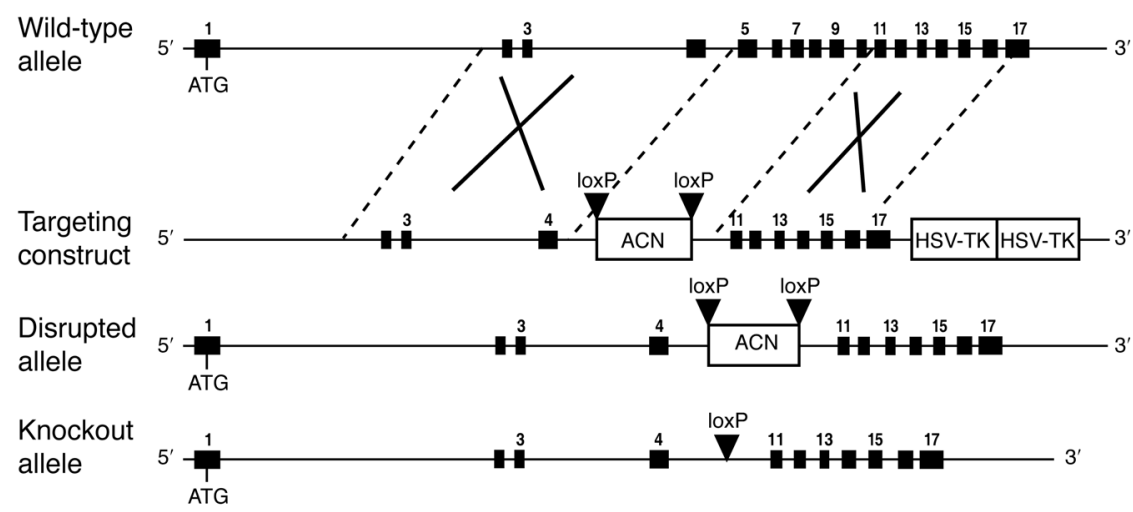

Figure 1

Tissue distribution of GBA2 mRNA and protein and strategy to knock out Gba2. (A) The relative levels of GBA2 mRNA in the indicated pooled tissues of male mice $(n=6)$ were determined by real-time RT-PCR. Data were normalized to the threshold cycle value determined in the liver $\left(C_{T}=28\right)$. (B) Microsomal membranes were prepared and pooled from the indicated tissues (+/+, wild-type; -/-, homozygous) isolated from male mice $(n=6)$. Aliquots of protein $(30 \mu \mathrm{g})$ were resolved by SDS-PAGE, transferred to nitrocellulose, and then blotted with an antibody raised against amino acids 1-508 of the GBA2 protein. To ensure equal amounts of protein were examined in each lane, bound GBA2 antibody complexes were removed and the filter was probed a second time with an antiserum raised against calnexin. (C) Schematics of the Gba2 wild-type allele, the targeting construct used to induce a deletion mutation by homologous recombination in ES cells, the predicted disrupted allele, and the final knockout allele are shown. Numbered black boxes indicate exons, and ATG represents the initiation codon specified within exon 1. Black triangles indicate positions of loxP sites recognized and cleaved by Cre recombinase. HSV-TK, herpes simplex virus thymidine kinase. ACN, angiotensinogen converting enzyme promoter-Cre recombinase-neomycin resistance.

characterized human enzyme (13). Database searches with the mouse and human cDNA sequences revealed apparent orthologs of the GBA2 enzyme in species ranging from Drosophila (CG33090 gene) to Arabidopsis (MUJ8.8 gene) to vertebrates, suggesting that the protein was conserved and thus of functional importance. No overt sequence identity was detected between GBA2 and other proteins in the database. Real-time RT-PCR was used to determine the tissue distribution of the mouse GBA2 mRNA. Whereas the human GBA2 mRNA is abundant in brain, heart, skeletal muscle, and kidney (13), the mouse mRNA was most abundant in the testis and brain, with lesser amounts present in 14 other tissues (Figure 1A).

Two fragments of the mouse GBA2 protein spanning amino acids 1-508 and 547-716 were expressed in E. coli, purified, and used to raise polyclonal antisera in rabbits. The antiserum generated against the longer recombinant antigen recognized a GBA2 protein of the expected molecular weight $(\sim 110,000)$ that was absent in GBA2 knockout mice (see below) and most abundant in the brains, livers, and testes (Figure 1B). The amount of GBA2 mRNA was proportional to the level of protein in the tissues examined with the exception of the liver, where the protein was more abundant than would be expected from the level of mRNA (Figure 1, compare A and B). Similar immunoblotting results were obtained with the antiserum raised against the shorter recombinant GBA2 fragment (data not shown).

Knockout of mouse Gba2 gene. Comparison of the GBA2 cDNA and genome sequences indicated that mouse Gba2 was located on chromosome 4B1 and contained 17 exons (Figure 1C). Neighboring genes were located $0.4 \mathrm{~kb} \mathrm{5}$ (1110029E03Riken) and $0.1 \mathrm{~kb}$ $3^{\prime}$ (Creb3) of the Gba2 locus, and for this reason a knockout strategy was designed to ensure that the introduced mutation would not affect expression of these closely linked genes. A targeting construct was assembled to delete exons 5-10 of Gba2 and to introduce a selectable marker following homologous recombination in ES cells. The selectable marker conferred neomycin resistance and contained a Cre recombinase gene linked to a testis-specific promoter (18). Following transmission of the disrupted allele through the germ line of male mice, the Cre recombinase removed the selectable marker, leaving behind a loxP site at the position of the introduced deletion in the knockout allele (Figure 1C). Subsequent real-time RT-PCR experiments showed that expression of the 2 immediate flanking genes was not altered in $\mathrm{Gba2}^{-/-}$mice (data not shown).

Characterization of $\mathrm{Gba2}^{-/-}$mice. A PCR-based genotyping assay was developed to follow inheritance of the deleted Gba2 allele 
A

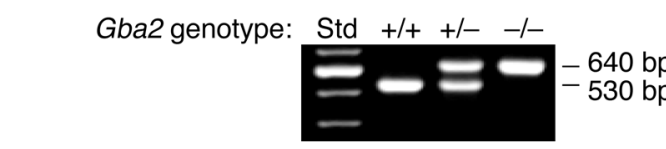

C

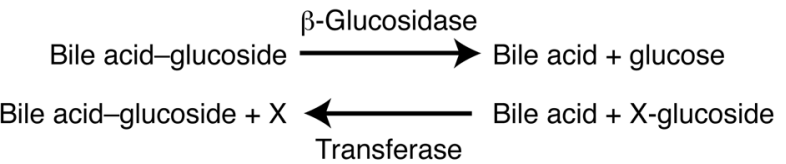

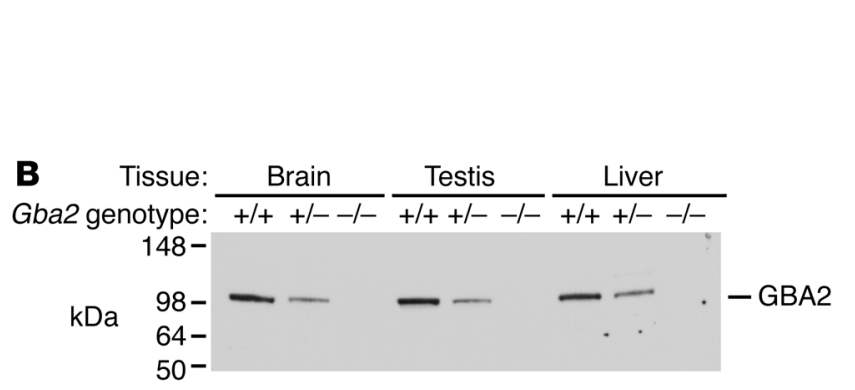
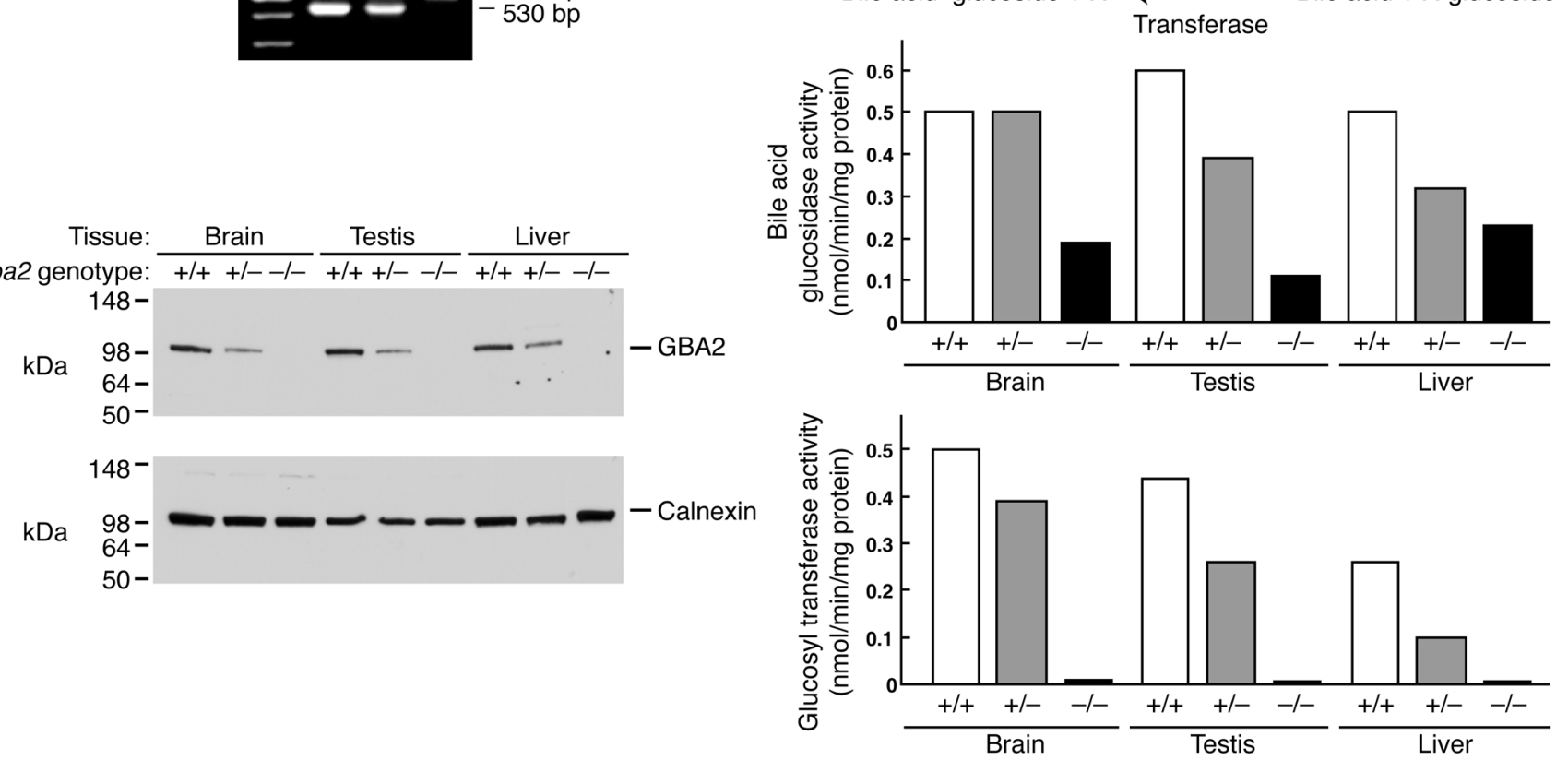

Figure 2

Characterization of Gba2-/- mice. (A) PCR genotyping of Gba2 wild-type, heterozygous (+/-), and homozygous genomic DNA. A 640-bp product was generated from the mutant allele, while a 530-bp product was produced from the wild-type allele. (B) Immunoblotting of GBA2 protein levels in pooled brains, testes, and livers from Gba2 wild-type, heterozygous, and homozygous mice ( $n=6$ per genotype). The filter of the upper blot was stripped of antibody-antigen complexes and reprobed with an antiserum recognizing calnexin to serve as a loading control. (C) Bile acid glucosidase and transferase enzyme activities were determined in the brains, testes, and livers of Gba2 wild-type, heterozygous, and homozygous mice. " $X$ " in the reaction shown is either dolichyl phosphoglucose or octyl $\beta$-glucoside.

(Figure 2A) and revealed the expected proportions of heterozygous and homozygous offspring. Immunoblotting experiments showed that the level of GBA2 protein expressed in the brains, testes, and livers of $\mathrm{Gba2}^{+/-}$mice was half that of wild-type controls and that Gba2/- mice expressed no detectable protein (Figure $2 \mathrm{~B}$ ). The GBA2 enzyme catalyzes both the cleavage and formation of bile acid-glucose conjugates $(10,16)$ (Figure $2 \mathrm{C}$ ). Of these 2 reactions, bile acid glucosidase activity in the brain was unchanged in $\mathrm{Gba2}^{+/-}$ mice and was reduced by approximately $50 \%$ in $\mathrm{Gba2}^{-/-}$mice. The activity in the testes and livers was decreased by approximately $30 \%$ in $\mathrm{Gba2} 2^{+/-}$animals and by approximately $50 \%-85 \%$ in $\mathrm{Gba2}-1$ - mice. In contrast, bile acid glucosyltransferase activity was decreased by $20 \%-50 \%$ in the tissues of $\mathrm{Gba2}^{+/-}$mice and reduced to undetectable levels in Gba2-/- animals (Figure 2C). These data indicated that GBA2 was responsible for a variable amount of bile acid glucosidase activity in these 3 tissues and for most if not all of the measurable bile acid glucosyltransferase activity.

The body weights of adult Gba2 $2^{-/-}$mice were normal, and tissues in the mutant mice including the liver, spleen, and brain weighed the same as those in control animals (Table 1). In contrast to these findings, the testes of the knockout mice were significantly smaller $(P<0.003)$ than those of wild-type mice.

Lipid and bile acid metabolism in Gba2-/- mice. Plasma cholesterol and triglyceride levels were similar in mice of different Gba2 genotypes (Table 1), and analysis of plasma by size-exclusion chromatography revealed a normal distribution and amount of choles- terol present in the various subclasses of lipoprotein particles (data not shown). HPLC analyses revealed bile acid pool size and composition in $\mathrm{Gba2}^{-/-}$mice that were not significantly different from wild-type controls (Table 1). Analysis of fecal bile acid excretion rates showed that the synthesis of bile acids was similar in knockout and wild-type mice (Table 1). In agreement with these findings, intestinal cholesterol absorption in the mutant mice was not different from that in control mice (Table 1). We concluded from these experiments that GBA2 did not play a major role in cholesterol and bile acid metabolism and that the enzyme might act on alternate substrates in vivo.

Fecundity defect in $\mathrm{Gba}^{-/-}$mice. Crosses between male and female $\mathrm{Gba2}^{+/+}$mice produced an average litter size of 8.1 pups, and crosses between $\mathrm{Gba2}^{+/-}$mice yielded a similar litter size of 7.5 pups (Table 2). In contrast, mating of Gba2-/- mice produced an average litter size of only 2.8 pups. When $G b a 2^{-/-}$females were crossed with wild-type males, the litters were of normal size (7.4 pups); however, crosses between $\mathrm{Gba2}^{-/-}$males and wild-type females produced small litters (3.0 pups). These data indicated that loss of the GBA2 enzyme in male mice caused a reduction in fecundity but had no effects on reproductive fitness in female mice.

Sperm morphology in Gba2 $2^{-/}$mice. Fecundity defects in males can arise from a failure of spermiogenesis or fertilization. To distinguish between these possibilities, we first examined the structure

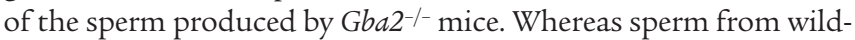
type mice had a normal sickle-headed morphology when examined 


\section{Table 1}

Physical and physiologic characteristics of $\mathrm{Gba2}^{+/+}$and

Gba2 $^{-1-}$ mice

\begin{tabular}{|c|c|c|}
\hline Parameter & $\mathrm{Gba2}^{+/+}$ & Gba2-- \\
\hline Body wt (g) & $23.8 \pm 1.1$ & $25.8 \pm 1.9$ \\
\hline Heart wt $(\%)^{A}$ & $0.59 \pm 0.039$ & $0.52 \pm 0.019$ \\
\hline Brain wt $(\%)^{A}$ & $1.83 \pm 0.068$ & $1.66 \pm 0.116$ \\
\hline Liver wt $(\%)^{A}$ & $3.95 \pm 0.132$ & $3.78 \pm 0.187$ \\
\hline Spleen wt $(\%)^{A}$ & $0.28 \pm 0.04$ & $0.2 \pm 0.015$ \\
\hline Kidney wt $(\%)^{A}$ & $1.44 \pm 0.025$ & $1.42 \pm 0.023$ \\
\hline Thymus wt $(\%)^{A}$ & $0.67 \pm 0.039$ & $0.68 \pm 0.035$ \\
\hline Lung wt $(\%)^{A}$ & $0.60 \pm 0.013$ & $0.59 \pm 0.026$ \\
\hline Testes wt $(\%)^{A, B}$ & $0.93 \pm 0.045$ & $0.72 \pm 0.03$ \\
\hline Plasma triglyceride (mg/dl) & $126.1 \pm 20.0$ & $96.7 \pm 15.6$ \\
\hline Plasma cholesterol (mg/dl) & $103.2 \pm 4.2$ & $96.4 \pm 5.8$ \\
\hline $\begin{array}{l}\text { Bile acid pool size } \\
(\mu \mathrm{mol} / 100 \mathrm{~g} \text { body } w \mathrm{t})\end{array}$ & $93.2 \pm 7.8$ & $92.6 \pm 6.5$ \\
\hline $\begin{array}{l}\text { Cholic/muricholic acid ratio } \\
\text { in bile acid pool }\end{array}$ & 1.6 & 1.0 \\
\hline $\begin{array}{l}\text { Fecal bile acid excretion rate } \\
\text { (mmol/d/100 g body wt) }\end{array}$ & $23.5 \pm 2.7$ & $19.2 \pm 1.6$ \\
\hline Intestinal cholesterol absorption (\%) & $66.2 \pm 3.9$ & $59.0 \pm 3.1$ \\
\hline
\end{tabular}

Values are mean \pm SEM. Weights were derived from 12 male mice, 3-4 months of age, for each genotype. Physiologic measurements were made in 6-10 male or female mice in 2 or more experiments. ATissue weights are shown as percent relative to body weight. ${ }^{\mathrm{B}} P<0.0029$; Gba2 $^{-/-}$versus $\mathrm{Gba2}^{+/+}$.

by light microscopy, Gba2 ${ }^{-/}$sperm had abnormally large, round heads (globozoospermia; Figure 3A). Immunofluorescent staining of wild-type sperm with a lectin that recognizes carbohydrates in the acrosome, a DNA-binding dye (DAPI) that labels nuclei, and a dye that selectively binds mitochondria (MitoFluor Red 589) revealed the classic outline of mammalian sperm (Figure $3 \mathrm{~B}$ ). In comparison, $\mathrm{Gba2}^{-/-}$sperm exhibited diffuse lectin-positive staining in round heads, indicating that an acrosome-like structure was present but disordered in these cells, and the presence of mitochondria in both the head and the sheath of the sperm. Under the electron microscope, the heads of wild-type sperm showed ordered mitochondria in the sheath, well-defined acrosomes at the tips, and large, dense nuclei in the heads (Figure 3C). In contrast, $\mathrm{Gba2}^{-/-}$sperm had distended round heads that lacked an obvious acrosome, disordered mitochondria in the sheaths and heads, and dense pyknotic nuclei.

Sperm parameters in $\mathrm{Gba2}^{-/-}$mice. To determine sperm number, epididymides were dissected from Gba2 wild-type and knockout mice, and sperm were removed by mincing the organ. Sperm counts were significantly lower $(P<0.02)$ in the mutant mice (Table 3). The percentage of mature, motile sperm in the caudal epididymis was similarly reduced. Motion studies indicated that mature sperm from knockout mice exhibited slower path, linear, and track velocities compared with sperm of wild-type mice (Table 3 ).

Defective in vitro fertilization. Mature sperm were collected from cauda epididymides of male $\mathrm{Gba2}^{+/+}$and $\mathrm{Gba2}^{-/-}$animals and incubated in fertilization medium for 90 minutes, after which $1 \times 10^{6} \mathrm{sperm} / \mathrm{ml}$ were incubated for 5 hours with oocytes in cumulus masses isolated from wild-type female mice. Examination by light microscopy showed that sperm from $\mathrm{Gba2}^{+/+}$mice bound in large numbers to the zona pellucida of the egg, while those from $\mathrm{Gba}^{-/-}$mice did not (Figure 4). The efficiency of blastocyst formation when wild-type sperm were incubated with wild-type oocytes was $31 \%$ (20 blastocysts developed from 64 eggs); when sperm from $\mathrm{Gba2}^{+/-}$males were incubated with wild-type oocytes, the efficiency was $43 \%$ (19 blastocysts from 44 eggs). In contrast, no blastocysts were formed when $\mathrm{Gba2}^{-/-}$sperm were cocultured with wild-type eggs (0 blastocysts from 63 eggs).

GBA2 expression in testis. During spermatogenesis, individual germ cells are surrounded by the lamellae of Sertoli cells within the testis. Interactions between the 2 cell types are required for proper cytological differentiation of sperm, their movement along the seminiferous tubules, and release into the rete testis (19). This symbiotic relationship raised the question of whether the anatomical and functional defects observed in $\mathrm{Gba2}^{-/-}$sperm were due to loss of GBA2 expression in germ cells or Sertoli cells. Histological analyses of $\mathrm{Gba2}^{-/-}$testes showed slightly distended lumens in individual seminiferous tubules and increased numbers of pyknotic germ cells (Figure 5A). Consistent with the latter observation, TUNEL staining revealed a significantly increased number of apoptotic cells in the testes of $\mathrm{Gba2}^{-/-}$mice versus $\mathrm{Gba2}^{+/+}$mice $\left(199 \pm 15\right.$ versus $57 \pm 7$ expiring cells; $\left.P<5.5 \times 10^{-6}\right)$. Immunofluorescent staining for GBA2 revealed expression in Sertoli cells that overlapped that of tyrosine-tubulin (Figure 5, B and C), a posttranslationally modified form of tubulin selectively expressed in this testicular cell type (20). The GBA2 stain was distinct from that of deleted in Azoospermia-like (DAZL) (Figure 5D), a germ cell marker protein (21).

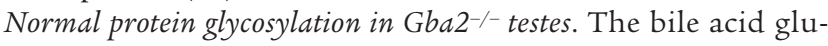
cosidase activity of GBA2 is inhibited by iminosugars such as 1-deoxynojirimycin $(10,12)$, and administration of alkylated iminosugars to mice causes male infertility and globozoospermia (22-24). 1-Deoxynojirimycin inhibits glucosidases involved in the processing of asparagine-linked carbohydrates attached to proteins as well as those involved in the biosynthesis of glycolipids $(25,26)$. These observations suggested that the accumulation of improperly glycosylated proteins or glycolipids within the testes might underlie the decreased fertility observed in the $\mathrm{Gba}^{-/-}$mice. To distinguish between these 2 possibilities, we first carried out a series of lectin blotting experiments to determine whether protein glycosylation was aberrant in the mutant mice. Membrane proteins were isolated from the testes of wild-type and knockout mice and separated by SDS-PAGE. Following transfer to membranes, glycosylated proteins were visualized by probing with 8 different lectin-horseradish peroxidase complexes. Multiple different proteins were detected by each lectin; however, the patterns of proteins observed in mice of different Gba2 genotypes

\section{Table 2}

Fecundity defect in Gba2-- mice

\begin{tabular}{lcccc}
\multicolumn{2}{c}{ Gba2 genotype } & $\begin{array}{c}\text { No. } \\
\text { matings }\end{array}$ & $\begin{array}{c}\text { No. } \\
\text { pregnancies }\end{array}$ & $\begin{array}{c}\text { Mean } \\
\text { litter size }\end{array}$ \\
Male & Female & & & \\
$+/+$ & $+/+$ & 31 & 31 & 8.1 \\
$+/-$ & $-/+$ & 35 & 35 & 7.5 \\
$+/+$ & $-/-$ & 10 & 10 & 8.4 \\
$-/-$ & $+/+$ & 9 & 3 & 3.0 \\
$-/-$ & $-/-$ & 64 & 40 & 2.8
\end{tabular}

Mean litter size was calculated as the number of live pups born per the number of litters. Data were derived from matings between animals less than 6 months of age. 


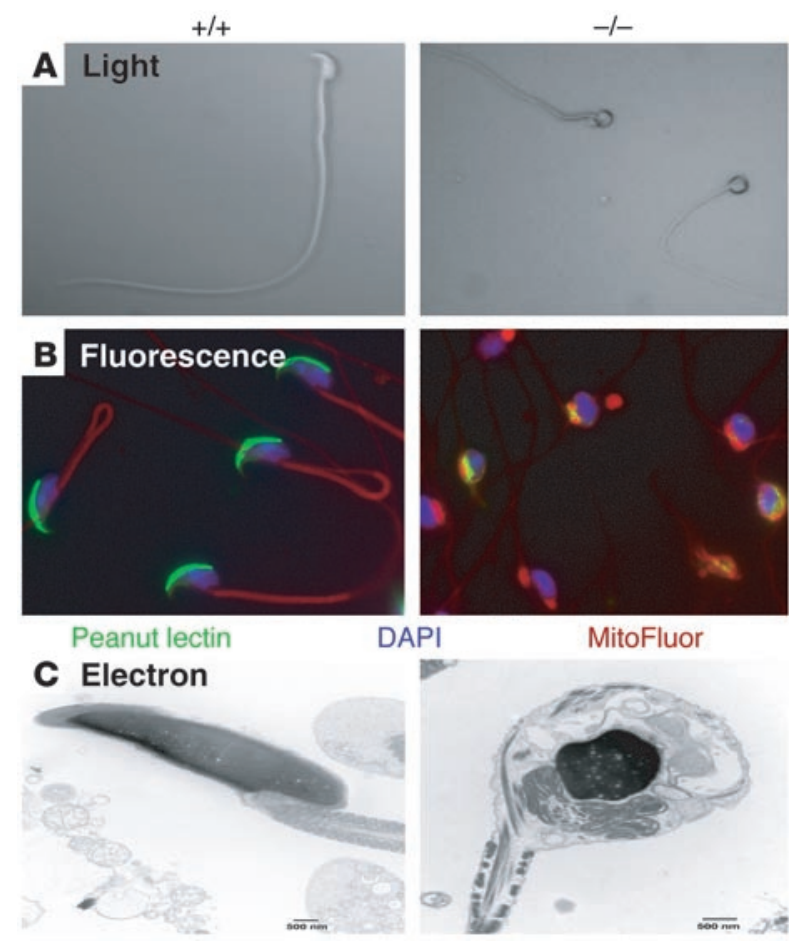

were similar (data not shown). These results suggested that protein glycosylation was normal in the Gba2 $2^{-/}$mice and that GBA2 did not utilize glycoproteins as substrates.

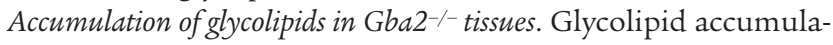
tion in the mutant mice was monitored by extraction and TLC using 2 different methods $(27,28)$. Comparison of testicular glycolipids separated by 1 -dimensional TLC revealed normal levels of several fucosylated lipids known to be required for male fertility (28) in the knockout tissue and the gradual accumulation of a glycolipid species that migrated to a position on the silica plate similar to those of 2 glucosylceramide standards (Figure 6A). The accumulation of a similar glycolipid species in the brains of male and female $\mathrm{Gba}^{-/-}$mice was observed after extraction and separation by a 2-dimensional TLC method (ref. 27 and data not shown). The identity of the glycolipid that accumulated in the testes of the mutant mice was determined by electrospray ionization-mass spectrometry. Precursor ion and neutral loss scans indicated that the accumulated glycolipid observed on the orcinol-stained TLC plate consisted of mixture of d18:1/C16:0 and d18:1/C18:0 monohexosylceramides (Figure 6B). Analysis of the accumulated lipid by normal phase liquid chromatography and mass spectrometry-mass spectrometry indicated that the hexose sugar was glucose. Similar structural results were obtained when glycolipids extracted from the liver and brain were analyzed (data not shown).

To determine whether GBA2 utilizes glucosylceramide as a substrate, cDNAs encoding the mouse and human enzymes were introduced into cultured simian COS cells, and the ability of the transfected cells to catalyze cleavage of a fluorescently derivatized glucosylceramide was monitored by spectrophotometry (29). Glucosylceramidase activity in mock-transfected cells was $0.024 \mathrm{nmol} / \mathrm{min} / \mathrm{mg}$, whereas this activity increased to $0.33 \mathrm{nmol} / \mathrm{min} / \mathrm{mg}$ in cells transfected with human GBA2 cDNA and to $0.18 \mathrm{nmol} / \mathrm{min} / \mathrm{mg}$ in cells transfected with mouse GBA2 cDNA (Figure 6C). For comparison purposes, cell extracts were assayed for bile acid glucosidase activ-

\section{Figure 3}

Sperm morphology in Gba2 wild-type and knockout mice. (A) Photomicrographs taken on light microscope showing normal sickle-headed sperm in wild-type mice and round-headed sperm in knockout mice. Original magnification, $\times 400$. (B) Fluorescent staining for cell nuclei with DAPI (blue), immunofluorescent staining of acrosomes with peanut lectin (green), and fluorescent staining of mitochondria (red). Original magnification, $\times 630$. (C) Electron microscopic analyses of sperm showing abnormal head shape, nuclear organization, and distribution of mitochondria in knockout sperm. Scale bars are indicated in individual panels.

ity using lithocholic acid glucoside as a substrate. This activity was increased in transfected cells relative to mock-transfected cells and was 40-50 times higher than that measured with the glucosylceramide substrate (Figure 6C). To show that GBA2 cleaved authentic glucosylceramide, transfected human embryonic kidney 293 cells were incubated with $\left[{ }^{14} \mathrm{C}\right]$ glucosylceramide, and radiolabeled lipids were examined after resolution by TLC. As shown in Figure 7D, cells transfected with the mouse GBA2 expression vector produced large amounts of ceramide, whereas mock-transfected cells did not.

Subcellular accumulation of glycolipids and localization of GBA2. Periodic acid Schiff staining of testes from 6- and 14-month-old Gba2-/- mice revealed the gradual accumulation of small glycolipidcontaining vesicles within Sertoli cells that were not present in agematched $\mathrm{Gba2}^{+/+}$testes (Figure 7, A-D). Immunofluorescent staining of COS cells with an antibody directed against GBA2 revealed a reticular staining pattern characteristic of a resident protein of the ER that did not overlap with that of lysosomes (Figure 7, E and F).

\section{Discussion}

The present study shows that the GBA2 enzyme, initially identified as a microsomal bile acid $\beta$-glucosidase in vitro, functions as a glucocerebrosidase in vivo. The reassignment of the enzyme to glycolipid metabolism is based on 2 observations in $\mathrm{Gba}^{-/-}$mice: first, enzyme loss did not disrupt cholesterol or bile acid metabolism; and second, tissues from the knockout mice in which GBA2 is normally expressed, including the testis, liver, and brain, accumulated glucosylceramides. Consistent with these observations, recombinant GBA2 enzyme exhibited glucosylceramidase activity in vitro. The accumulation of glycolipids in the Sertoli cells of the testis gave rise to misshapen sperm and impaired fertility in the knockout mice. In contrast, while these same glycolipids built up in the liver and brain, they did not appear to grossly affect organ function. We conclude that GBA2 is a glucocerebrosidase whose loss leads to glycolipid accumulation and a form of ER storage disease.

\section{Table 3}

Sperm count, motility, and swim speeds

\begin{tabular}{lcc} 
Parameter & Gba2 $^{+/+}$ & \multicolumn{1}{c}{ Gba2 $^{-/-}$} \\
Count $(\mathrm{no} . / \mathrm{ml})^{\mathrm{A}}$ & $1.2 \times 10^{7} \pm 1 \times 10^{6}$ & $7.1 \times 10^{6} \pm 1.4 \times 10^{6}$ \\
Motility $(\%)$ & $56 \pm 1.3$ & $33 \pm 3.1$ \\
Mean velocity $(\mu \mathrm{m} / \mathrm{s})^{\mathrm{A}, \mathrm{B}}$ & $126 \pm 2.8$ & $104 \pm 7.0$ \\
Linear velocity $(\mu \mathrm{m} / \mathrm{s})^{\mathrm{A}, \mathrm{B}}$ & $96 \pm 4.6$ & $70 \pm 5.2$ \\
Curvilinear velocity $(\mu \mathrm{m} / \mathrm{s})^{\mathrm{A}, \mathrm{B}}$ & $257 \pm 4.0$ & $203 \pm 17$
\end{tabular}

Values are mean \pm SEM derived from 6 male mice, 3-4 months of age, for each genotype. BValues from 300 sperm isolated from 4 animals of each genotype. ${ }^{\mathrm{A} P}<0.03$; $\mathrm{Gba2}^{-/-}$versus $\mathrm{Gba2}^{+/+}$. 
+/+ Sperm, +/+ Egg

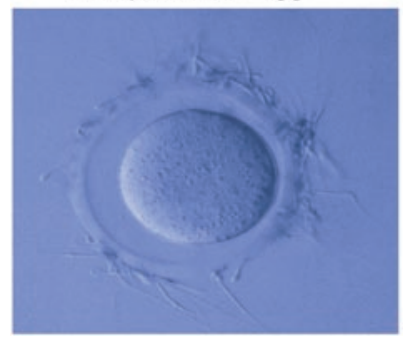

Figure 4

Failure of sperm from $\mathrm{Gba}^{-1-}$ mice to bind the zona pellucida. Cumulus enclosed oocytes from $\mathrm{Gba2}^{+/+}$mice were incubated for 5 hours with either $\mathrm{Gba2}^{+/+}$sperm (left panel) or $\mathrm{Gba2}^{-/-}$sperm (right panel) and then examined by light microscopy. Sperm from knockout mice were deficient in zona pellucida binding. Original magnification, $\times 160$.

The existence of nonlysosomal glucocerebrosidase activity in various human tissues and cell types was reported in the 1990s by Aerts and colleagues $(30,31)$. This activity was shown to be tightly associated with the membrane, selectively inhibited by hydrophobic deoxynojirimycin derivatives and the conjugated bile acid taurocholate, and present at normal levels in cells isolated from patients with Gaucher's disease. Although the enzyme responsible for this activity was never identified, the described biochemical properties are similar to those of GBA2, and it is therefore possible that the nonlysosomal glucocerebrosidase detected in these earlier studies was GBA2.

In vitro, GBA2 catalyzes the addition of glucose to lipid substrates and the hydrolysis of glycolipid conjugates. The fact that glucosylceramides accumulated in $\mathrm{Gba2}^{-/}$mice suggests that the preferred reaction direction in vivo, at least in the testis, liver, and brain, favors the $\beta$-glucosidase activity of the enzyme. The glucosyltransferase reaction may predominate in other tissues or the equilibrium may be regulated depending on the needs of the cell. Along these lines, glycolipids are typically synthesized in the ER and broken down in the lysosome (5), and it is conceivable that the need to catabolize glucosylceramides in the ER arises under some conditions and is met by the reversible GBA2 enzyme. Similarly, the glucosyltransferase activity may predominate with bile acid substrates in the liver to facilitate their disposal.

Both the GBA2 and the lysosomal acid-specific GBA1 deficient in Gaucher's disease hydrolyze glucosylceramides, and it is instructive to compare the 2 enzymes and the phenotypes arising from their loss. GBA2 is a microsomal enzyme that catalyzes the transfer of glucose to multiple lipid substrates as well as the hydrolysis of these conjugates, while GBA1 is a lysosomal enzyme that preferentially hydrolyzes glucosylceramides (32). Gba2-/- mice and patients with Gaucher's disease accumulate glucosylcerami-

\section{Figure 5}

Cell type specific expression patterns of GBA2, tyrosine-tubulin, and DAZL in testes from Gba2 wild-type and knockout mice. (A) H\&E staining of testis showing near-normal cellular organization of the gonads. (B) Immunofluorescent staining of GBA2 in Sertoli cells of the organ. (C) Immunofluorescent staining with antibodies that recognize tyrosine-tubulin, a Sertoli cell marker protein. (D) Immunofluorescent staining with antibodies that recognize DAZL, a germ cell marker protein. Scale bars are indicated in individual panels. des in multiple tissues; however, the pattern of deposition and its consequences are different in each. In the knockout mice, glycolipid accumulates in the ER while in subjects with Gaucher's disease, the lipid accumulates in the lysosome $(6,7)$. This difference in subcellular accumulation leads to globozoospermia and decreased fertility in GBA2-deficient male mice, whereas human males with Gaucher's disease are fertile (7). Although glycolipids build up in the tissues of the mutant mice, they do not cause organomegaly, whereas in subjects with Gaucher's disease these lipids accumulate in resident and infiltrating phagocytes and cause organ enlargement (7). Knockout mice lacking GBA1 die shortly after birth (33), whereas GBA2-deficient mice have normal life spans. The variation in phenotype arising from the loss of GBA1 versus GBA2 is most likely due to the unique tissue-specific expression patterns and subcellular localizations of these isozymes. These properties may also explain why the 2 enzymes do not appear to compensate for one another.

Two treatments are currently used for the management of Gaucher's disease. The most common treatment involves enzyme replacement therapy with recombinant GBA1, which reduces the accumulation of glucosylceramides in most peripheral tissues (34). A newer treatment, termed substrate reduction therapy, involves administration of $N$-butyldeoxynojirimycin, which decreases the biosynthesis of glucosylceramides and thereby reduces accumulation (8). $N$-butyldeoxynojirimycin is thought to act by inhibiting glucosylceramide synthetase, the first enzyme in the glycosphingolipid biosynthetic pathway. Because $N$-butyldeoxynojirimycin
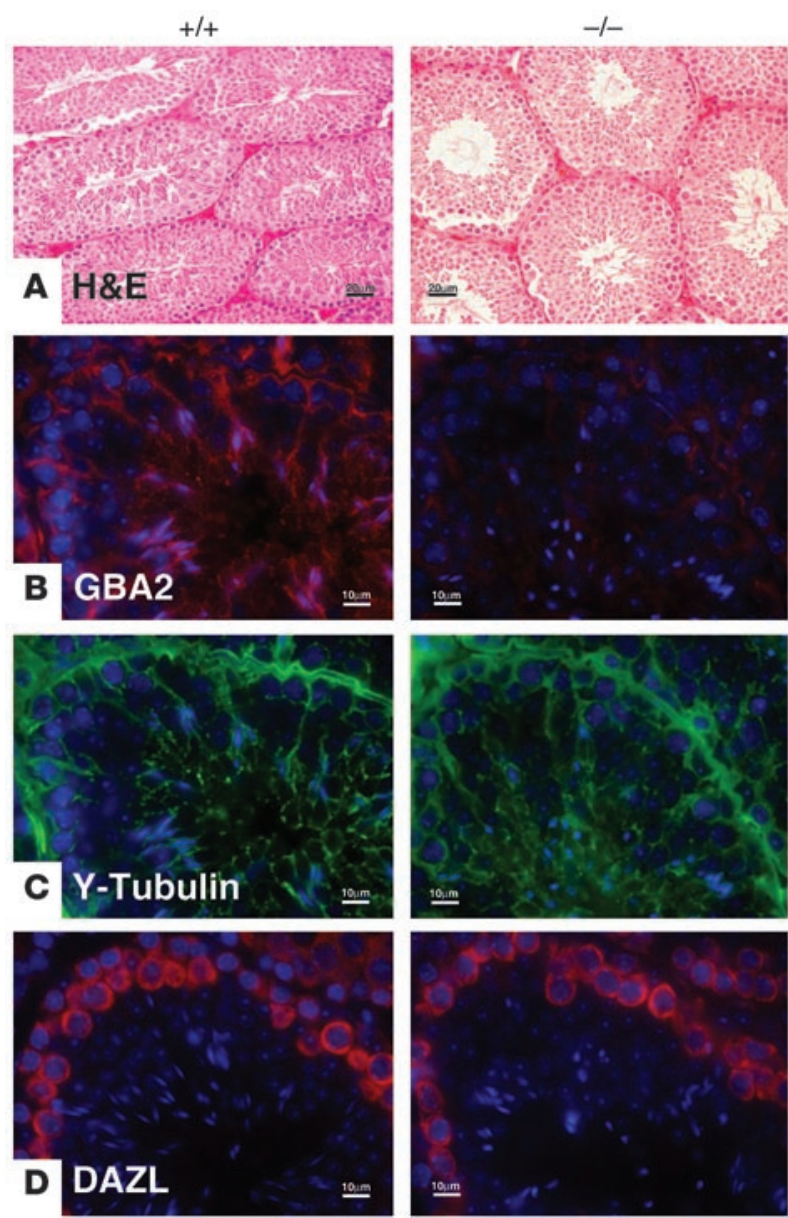
A

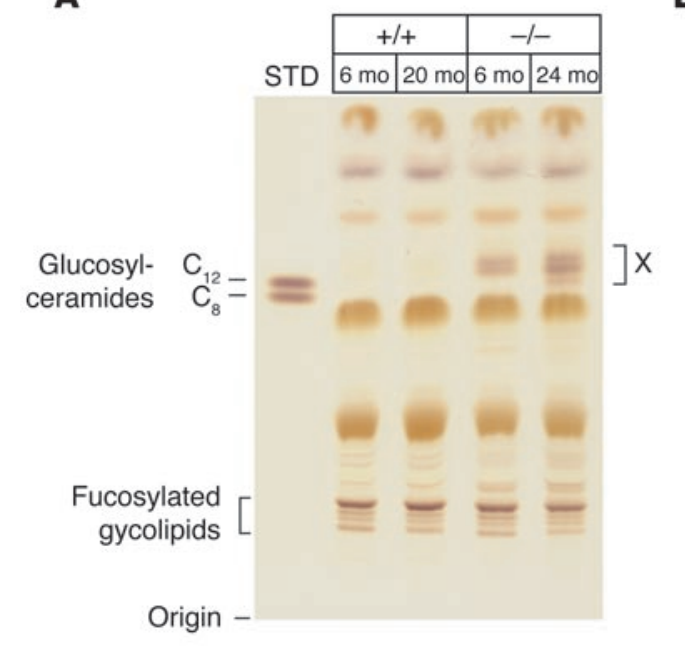

C

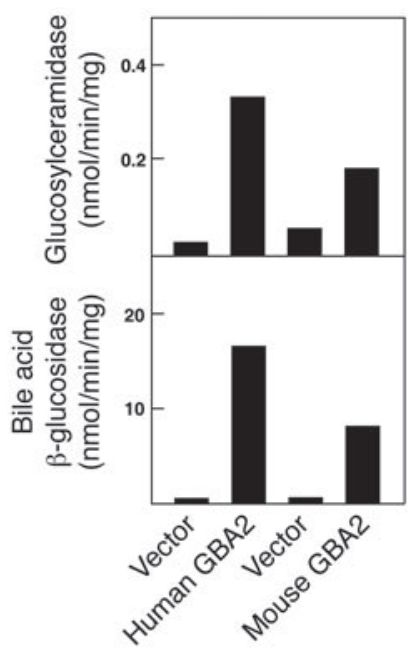

B

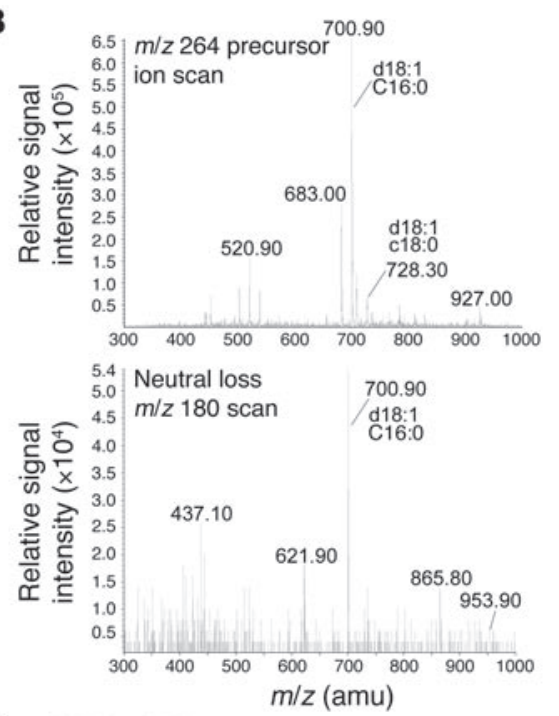

D pCMV-mGBA2 - +

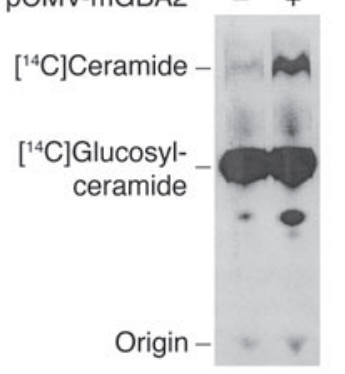

\section{Figure 6}

Analysis of glycolipids in Gba2 wild-type and knockout mice. (A) Glycolipids were extracted from testes of 6-, 20-, and 24-month-old mice, resolved by 1-dimensional TLC, and visualized by staining with orcinol. The positions of the origin and glucosylceramide standards are indicated at left. A glycolipid that accumulated with age in knockout tissue is marked " $X$ " at right. The positions to which several fucosylated glycolipids migrated to are indicated at left. (B) Structural analysis of glycolipid X shown in A. Glycolipids were extracted from the testes of $\mathrm{Gba}^{-1-}$ mice and resolved by 1-dimensional TLC, and glycolipid X was analyzed by mass spectrometry. An $\mathrm{m} / \mathrm{z} 264$ precursor ion scan revealed compounds of molecular masses (700.9 and 728.3) characteristic of monohexosylceramides containing sphingosine (d18:1) and either 16:0 or 18:0 fatty acyl groups. A neutral loss scan for $\mathrm{m} / \mathrm{z} 180$ diagnostic for glucose- or galactose-containing monohexosylceramides revealed a major compound of mass 700.9. (C) Expression of mouse and human GBA2 in COS cells and measurement of glucosylceramidase and bile acid glucosidase enzyme activities. Cells were transfected with the indicated plasmid DNA, and lysates were assayed for enzyme activity using fluorescently labeled glucosylceramide or bile acid glucoside substrates. (D) Expression of mouse GBA2 (mGBA2) in human embryonic kidney 293 cells and measurement of glucosylceramidase activity. Cells were transfected and assayed for enzyme activity using $\left[{ }^{14} \mathrm{C}\right]$ glucosylceramide. The positions of the origin and to which authentic glucosylceramide and ceramide standards migrated to are indicated at left. pCMV-mGBA2, expression plasmid encoding mouse GBA2 enzyme.

causes globozoospermia when administered to rodents (22), male patients with Gaucher's disease who receive the drug are advised to take appropriate birth control measures. Given the expression of GBA2 in the Sertoli cells of wild-type mouse testis, the presence of globozoospermia in the GBA2 knockout mice, and the ability of alkylated deoxynojirimycin derivatives to inhibit the GBA2 enzyme $(10,12)$, it is possible that inhibition of testicular GBA2 rather than glucosylceramide synthetase underlies this side effect in subjects with Gaucher's disease. If this hypothesis is correct, then more selective inhibitors of the glucosylceramide synthetase may be useful in the treatment of Gaucher's disease, while GBA2-specific inhibitors may be useful as male contraceptives.

Why does loss of an enzyme that is selectively expressed in Sertoli cells and that hydrolyzes glucosylceramide give rise to malformed sperm in $\mathrm{Gba2}^{-/-}$mice? Sertoli cells play an essential role in the differentiation and maturation of germ cells (19), and our current results suggest that catabolism of glycolipids by the GBA2 enzyme is an important aspect of this process. The source of the glycolipids that accumulate in the testes of the knockout mice is not known, but by analogy to patients with Gaucher's disease in whom these lipids accumulate in macrophages by phagocytosis (7), the interesting possibility is raised that glucosylceramides are normally transferred from developing germ cells to Sertoli cells for subsequent breakdown. Loss of the GBA2 enzyme causes glucosylceramide accumulation in Sertoli cells, which may in turn further disrupt transport of glycolipid from germ cells leading to the formation of abnormal sperm. There are extended Sertoli-germ cell contacts through which glycolipid transport could take place, including desmosomes, gap junctions, and 2 anatomically unique contacts referred to as Sertoli ectoplasmic junctional specializations and the tubulobulbar complex (19). It also is possible that the source of glycolipid is the Sertoli cell itself and that accumulation disrupts normal Sertoli-germ cell interactions, leading to malformed sperm. The cellular source of the accumulating glucosylceramide and the mechanism of toxicity may be revealed by further histological and biochemical studies of $\mathrm{Gba}^{-/-}$mice.

Globozoospermia is an infrequent cause of infertility in human males (35), and while mutations in several mouse genes includ- 

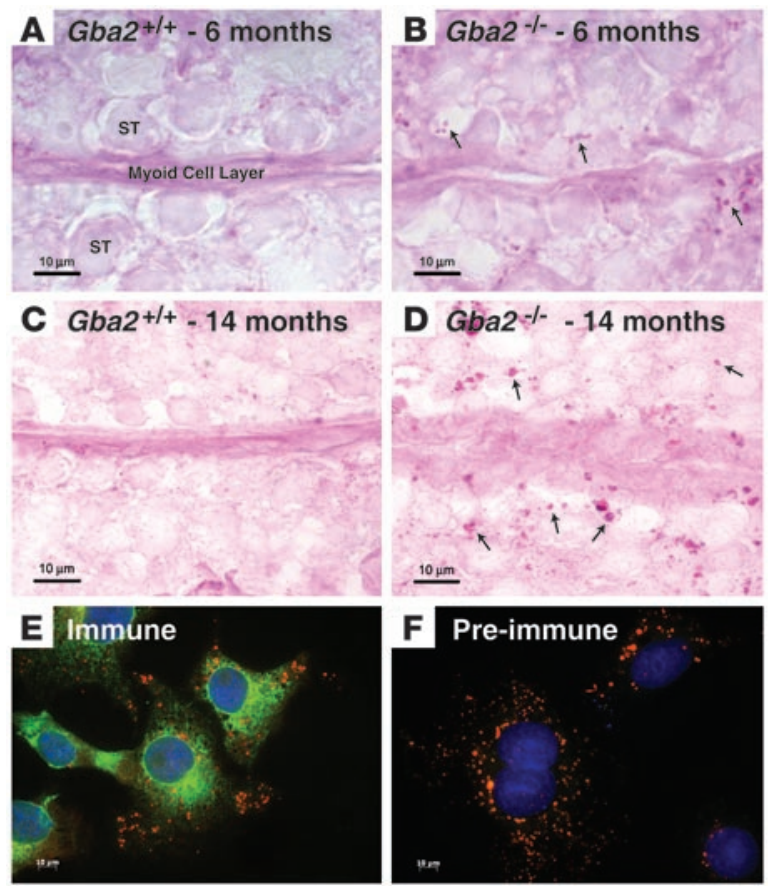

ing casein kinase II alpha (36), the Golgi-associated PDZ- and coiled-coil motif-containing protein (37), and Gba2 give rise to round-headed sperm, the genetic basis of the human inherited disease is not known. To determine if mutations in human GBA2 were the cause of globozoospermia, we sequenced the coding regions of the gene in affected males of 3 unrelated families from Britain (38), Canada (39), and Germany (40). No mutations in $G B A 2$ were detected in these subjects, suggesting that loss of this enzyme does not underlie all cases of globozoospermia in human males. Genetic screens in other affected individuals (41) may reveal mutations in GBA2.

\section{Methods}

Construction of Gba2 knockout mouse. A targeting vector composed of a $5.5-\mathrm{kb}$ long arm, a 2.0-kb short arm, 2 copies of a viral thymidine kinase gene conferring sensitivity to gancyclovir, and a DNA fragment specifying the angiotensinogen converting enzyme promoter-Cre recombinase-neomycin resistance cassette (18), was assembled in the pPollishort-neoPA-HSVTK plasmid (42). ES cells derived from the $129 \mathrm{~S} 6 / \mathrm{SvEv}$ mouse strain were electroporated, selected, and used to produce chimeric mice as described previously (43). Six chimeric male mice in which more than $70 \%$ of the genome was contributed by the ES cells were crossed with female C57BL/6J mice to generate independent lines of animals carrying the disrupted Gba2 allele. Routine genotyping of mice was performed by PCR on genomic DNA extracted from tails using a direct lysis kit (102-T; Viagen Biotech) with the following oligonucleotides: primer 1, 5'-GTGCTGGCTCACTGAGCTGGA-3'; primer 2, 5'-CCAGTCAGCAGTATCATGAATCAA-3'; primer 3, 5'-GCATGTACAACACATA-CGATGTCCA- $3^{\prime}$. All experiments involving animals were approved by the University of Texas Southwestern Institutional Animal Care and Use Committee.

Cholesterol and bile acid metabolism. Intestinal cholesterol absorption, bile acid excretion rates, pool size and composition, and tissue and serum lipid levels were measured as described previously (43-45).

Enzyme assays. Bile acid glucosidase and transferase activities were determined as described previously $(10,16)$. Glucosylceramidase activity was assessed as described previously (29).

\section{Figure 7}

Glycolipid accumulation in $\mathrm{Gba2}^{-/-}$mice and subcellular localization of GBA2. Glycolipids were visualized in the testes of 6- and 14-monthold wild-type (A and $\mathbf{C}$ ) and knockout (B and $\mathbf{D}$ ) mice by periodic acid Schiff staining of $8-\mu \mathrm{m}$ sections. Arrows indicate small, intensely stained deposits of glycolipids that accumulated with age in the knockout mice. ST, seminiferous tubule. (E) The subcellular localization of GBA2 (green) was determined by immunofluorescent staining of simian COS cells. Lysosomes (red) were identified by staining with LysoTracker. (F) COS cells stained with a preimmune serum and LysoTracker. Scale bars are indicated in individual panels.

Real-time RT-PCR. Total RNA was prepared from tissues using an RNA STAT-60 kit (Tel-Test Inc.). Equal amounts of RNA from 4 or 6 mice were pooled and treated with DNAse I (Ambion). First-strand CDNA was synthesized and subjected to real-time RT-PCR as described previously (46). The relative amount of a target mRNA was calculated using the comparative threshold cycle $\left(\mathrm{C}_{\mathrm{T}}\right)$ method. Cyclophilin mRNA was used as an invariant control. Oligonucleotide primer sequences used to detect GBA2 mRNA were 5'-GGAGACCTTTTCAAGCTAACAACAT-3' and 5'-GGTACCACCACTTCAAGTACCTCAA-3'.

Recombinant GBA2 protein expression and antibody production. A 500-bp cDNA fragment encoding amino acids 547-716 and a 1,500-bp DNA fragment encoding amino acids 1-508 of the mouse GBA2 protein were subcloned independently into the prokaryotic expression vector pET-45b(+) (Novagen). Recombinant protein was purified from E. coli by affinity chromatography on Ni-NTA columns. Aliquots of GBA2 protein $(500 \mu \mathrm{g})$ were mixed with $1 \mathrm{ml}$ Freund's adjuvant (ICN Biomedicals) and injected subcutaneously into rabbits. After 2 weeks, a booster dose of $250 \mu \mathrm{g}$ GBA2 protein was administered in Freund's incomplete adjuvant. The boosting procedure was repeated 4 times.

Immunoblot analyses of GBA2. Freshly isolated livers, testes, and brains were homogenized in 2 volumes of ice-cold sucrose buffer per gram of tissue (250 mM sucrose; $10 \mathrm{mM}$ Tris- $\mathrm{Cl}, \mathrm{pH} 7.4$; and $1 \mathrm{mM}$ sodium EDTA) supplemented with Complete Protease Inhibitors (EDTA-free; Roche Diagnostics). Homogenates were centrifuged at $800 \mathrm{~g}$ for 10 minutes at $4{ }^{\circ} \mathrm{C}$. Supernatants from this step were centrifuged for 20 minutes at $8,000 \mathrm{~g}$ at $4^{\circ} \mathrm{C}$, and the pellets were discarded. Supernatants were again centrifuged at $55,000 \mathrm{~g}$ for 30 minutes at $4^{\circ} \mathrm{C}$ in a Beckman TLA 100.2 rotor. The membrane pellets were resuspended in SDS-lysis buffer (1\% [wt/vol] SDS; 10 mM Tris-Cl, pH 6.8; $100 \mathrm{mM} \mathrm{NaCl} 11$ mM EDTA; and 1 mM EGTA) and analyzed by immunoblotting using standard procedures.

Microscopy. Gba2 $2^{+/+}$and $\mathrm{Gba}^{-/-}$mouse testes from 2-month-old animals were fixed for 4 hours in $4 \%(\mathrm{vol} / \mathrm{vol})$ paraformaldehyde before freezing in OCT cryoprotectant (Tissue-Tek; Sakura). Cryosections (8-10 $\mu \mathrm{m})$ were collected on poly-L-lysine-coated slides (Fisher Scientific). For immunofluorescent staining, sections were washed 3 times for 15 minutes with PBS, permeabilized with PBS containing $0.2 \%$ (vol/vol) Triton X-100, and blocked for 1 hour at room temperature with PBS containing $5 \%$ (wt/vol) bovine serum (Sigma-Aldrich), $0.025 \%$ Triton X-100, and 10\% (vol/vol) donkey serum (Sigma-Aldrich), followed by overnight incubation at $4{ }^{\circ} \mathrm{C}$ or room temperature with primary antibodies. Primary antibodies were used at dilutions of 1:1,000 to 1:2,000 and included rabbit polyclonal anti-GBA2 and anti-DAZL (21) antibodies (both protein A-purified) and a monoclonal anti-tyrosinetubulin antibody (TUB-1A2; Sigma-Aldrich). After 3 15-minutes washes with PBS, the sections were incubated with combinations of either Alexa Fluor 488-conjugated anti-rabbit secondary antibodies (diluted 1:2,000; Invitrogen) or Alexa Fluor 594-conjugated anti-mouse antibodies (1:2,000; Invitrogen) for 1 hour at room temperature in blocking buffer. Sections were washed 3 times for 15 minutes with PBS and mounted with ProLong Gold with DAPI 
(Invitrogen). Images were acquired on a Zeiss Axioplan 2 fluorescence microscope. Periodic acid Schiff staining to visualize glycolipids was performed using reagents from American Master*Tech Scientific. Visualization of lysosomes in living cells was performed using LysoTracker (Invitrogen).

For electron microscopy, caudal epididymal spermatozoa from adult mice were fixed in $3 \%$ (vol/vol) paraformaldehyde and $0.1 \%$ (vol/vol) glutaraldehyde in $0.1 \%$ phosphate buffer ( $\mathrm{pH} 7.4$ ), postfixed in $1 \%$ (wt/vol) osmium tetroxide in the same buffer, and embedded in a plastic resin according to standard procedures. Following sectioning, specimens were examined with a JEM-2100F transmission electron microscope (JEOL).

Sperm analyses. Epididymides from sexually mature mice were minced in PBS and incubated for 60 minutes at $37^{\circ} \mathrm{C}$. Debris was removed, and sperm were counted using a hemocytometer. For velocity measurements, mature sperm were isolated from the cauda of epididymides dissected from 12- to 16-week-old males. The tissue was placed in a 1-ml culture dish containing $1 \mathrm{ml} \mathrm{KSOM}$ medium (Specialty Media), and incisions were made at 4 sites with scissors. The dish was placed in a $37^{\circ} \mathrm{C}$ incubator for 15 minutes, and the medium containing the released sperm was decanted. Aliquots of the sperm suspension $(20 \mu \mathrm{l})$ were placed in an $80-\mu \mathrm{m}$-deep chamber and analyzed with the IVOS Sperm Analyzer (version 12; Hamilton Thorne Biosciences). Cell tracks were captured for 0.5 seconds at $60 \mathrm{~Hz}$. All procedures were performed at $37^{\circ} \mathrm{C}$. A minimum of 300 cells were analyzed from each animal ( $n=2$ per Gba2 genotype) to determine percentage of motile sperm, mean velocity (distance in $\mu \mathrm{m}$ traveled over a smoothed average path per second), linear velocity (the straight-line distance in $\mu \mathrm{m}$ between the initial and final locations of the sperm head divided by the total time in second), and curvilinear velocity (total distance swum by the sperm head from image to image divided by the total elapsed time).

In vitro fertilization. Procedures were performed as described previously (47). In brief, caudal epididymal sperm were collected in M16 medium (M7292; Sigma-Aldrich) supplemented with $30 \mathrm{mg} / \mathrm{ml} \mathrm{BSA}$ and capacitated for 90 minutes at $37^{\circ} \mathrm{C}$ in a $5 \% \mathrm{CO}_{2}$ atmosphere. Approximately $1 \times 10^{6}$ spermatozoa were added to $1-\mathrm{ml}$ drop cultures of fertilization medium containing unfertilized, cumulus-enclosed eggs collected approximately 13 hours after human chorionic gonadotropin treatment. Eggs were left with spermatozoa for approximately 5 hours, washed, placed in microdrop cultures of $\mathrm{KSOM}$ medium (Specialty Media), and incubated at $37^{\circ} \mathrm{C}$ in a $5 \%$ $\mathrm{CO}_{2}$ atmosphere. Blastocyst formation was assessed by light microscopy.

Glycolipid analyses. Extraction and analyses of glycolipids were performed as described previously $(27,28)$. Structural analyses were carried out on an
Applied Biosystems 4000 Q TRAP mass spectrometer with an electrospray source (48). Briefly, samples were resuspended in $0.5 \mathrm{ml}$ methanol/ $\mathrm{H}_{2} \mathrm{O}(9: 1$, $\mathrm{vol} / \mathrm{vol}$ ) and analyzed by direct infusion at a rate of $5 \mu \mathrm{l} / \mathrm{min}$ into the mass spectrometer. Scan types consisted of precursor ion scans for $264.4 \mathrm{~m} / \mathrm{z}$ representing sphingosine-based glycolipids and $266.4 \mathrm{~m} / z$ representing sphinganine-based glycolipids. Neutral loss scans for 162-Da and 180-Da masses representing those of $O$-linked hexose moieties were also performed. To determine whether the observed monohexosylceramides were glucosylceramides or galactosylceramides, samples from $\mathrm{Gba}_{2}-/$ mice were separated by normal phase liquid chromatography followed by mass spectrometry-mass spectrometry to distinguish these species (45).

Statistics. Student's unpaired $t$ test was used to compare data sets. A $P$ value less than 0.05 was considered significant.

\section{Acknowledgments}

We thank Daphne Head and Jill Fairless for technical assistance; Christopher Barratt, Renee Martin, and Hardi Schmiady for access to patient samples; Tim Quill for assistance with reproductive biology experiments; Alfred Merrill, Jr., M. Cameron Sullards, and Jeff McDonald for help with mass spectrometry experiments; and Jonathan Cohen, Joe Goldstein, Helen Hobbs, Jay Horton, and Alfred Merrill, Jr. for critical reading of the manuscript. This work was supported by grants from the NIH (HL20948, GM069338, and AR51943 to D.W. Russell), the Robert A. Welch Foundation (I-0971 to D.W. Russell), the Perot Family Foundation (to D.W. Russell), the Deutsche Forshungsgemeinschaft (MA 567/7-2 to S. Matern), and the Stipendium Program of the Medical Faculty, University of Aachen (to Y. Yildiz).

Received for publication May 26, 2006, and accepted in revised form July 25, 2006.

Address correspondence to: David W. Russell, Department of Molecular Genetics, University of Texas Southwestern Medical Center, 5323 Harry Hines Boulevard, Dallas, Texas 75390-9046, USA. Phone: (214) 648-2007; Fax: (214) 648-6899; E-mail: david.russell@ utsouthwestern.edu.

Yildiz Yildiz's present address is: Medizinische Klinik I, Universitatsklinikum Bonn, Bonn, Germany.
1. Simons, K., and Toomre, D. 2000. Lipid rafts and signal transduction. Nat. Rev. Mol. Cell Biol. 1:31-39.

2. Anderson, R.G., and Jacobson, K. 2002. A role for lipid shells in targeting proteins to caveolae, rafts, and other lipid domains. Science. 296:1821-1825.

3. Menaldino, D.S., et al. 2003. Sphingoid bases and de novo ceramide synthesis: enzymes involved, pharmacology, and mechanisms of action. Pharmacol. Res. 47:373-381.

4. Merrill, J.A.H. 2002. De novo sphingolipid biosynthesis: a necessary, but dangerous pathway. J. Biol. Chem. 277:25843-25846.

5. Perry, R.J., and Ridgway, N.D. 2005. Molecular mechanisms of ceramide transport. Biochim. Biophys. Acta. 1734:220-234.

6. Futerman, A.H., and van Meer, G. 2004. The cell biology of lysosomal storage disorders. Nat. Rev. Mol. Cell Biol. 5:554-565.

7. Beutler, E., and Grabowski, G.A. 2001. Gaucher disease. In The metabolic of molecular bases of inherited disease. C.R. Scriver, et al., editors. McGraw-Hill. New York, New York, USA. 3635-3668.

8. Futerman, A.H., Sussman, J.L., Horowitz, M., Silman, I., and Zimran, A. 2004. New directions in the treatment of Gaucher's disease. Trends Pharmacol. Sci.
25:147-151.

9. Henrissat, B., and Bairoch, A. 1996. Updating the sequence-based classification of glycosyl hydrolases. Biochem. J. 316:695-696.

10. Matern, H., Gartzen, R., and Matern, S. 1992. $\beta$-Glucosidase activity towards a bile acid glucoside in human liver. FEBS Lett. 314:183-186.

11. Gartung, C., Matern, S., and Matern, H. 1994. The submicrosomal localization of uridine 5 '-diphosphate-glucose dolichyl-phosphate glucosyltransferase and bile acid glucosyltransferase in the human liver. J. Hepatol. 20:32-40.

12. Matern, H., Heinemann, H., Legler, G., and Matern, S. 1997. Purification and characterization of a microsomal bile acid $\beta$-glucosidase from human liver. J. Biol. Chem. 272:11261-11267.

13. Matern, H., Boermans, H., Lottspeich, F., and Matern, S. 2001. Molecular cloning and expression of human bile acid $\beta$-glucosidase. J. Biol. Chem. 276:37929-37933.

14. Marschall, H.U., et al. 1994. Positions of conjugation of bile acids with glucose and $\mathrm{N}$-acetylglucosamine in vitro. J. Lipid Res. 35:1599-1610.

15. Marschall, H.U., Egestad, B., Matern, H., Matern, S., and Sjovall, J. 1987. Evidence for bile acid glucosides as normal constituents of human urine. FEBS Lett. 213:411-414.

16. Matern, H., Matern, S., and Gerok, W. 1984. Formation of bile acid glucosides by a sugar nucleotide-independent glucosyltransferase isolated from human liver microsomes. Proc. Natl. Acad. Sci.U.S. A. 81:7036-7040.

17. Wietholtz, H., Marschall, H.U., Reuschenbach, R., Matern, H., and Matern, S. 1991. Urinary excretion of bile acid glucosides and glucuronides in extrahepatic cholestasis. Hepatology. 13:656-662.

18. Bunting, M., Bernstein, K.E., Greer, J.M., Capecchi, M.R., and Thomas, K.R. 1999. Targeting genes for self-excision in the germ line. Genes Dev. 13:1524-1528.

19. Russell, L.D. 1980. Sertoli-germ cell interrelations. Gamete Res. 3:179-202.

20. Oke, B.O., and Suarez-Quian, C.A. 1993. Localization of secretory, membrane-associated and cytoskeletal proteins in rat testis using an improved immunocytochemical protocol that employs polyester wax. Biol. Reprod. 48:621-631.

21. Hamra, F.K., et al. 2002. Production of transgenic rats by lentiviral transduction of male germ-line stem cells. Proc. Natl. Acad. Sci. U. S. A. 99:14931-14936. 
22. Van der Spoel, A.C., et al. 2002. Reversible infertility in male mice after oral administration of alkylated imino sugars: a nonhormonal approach to male contraception. Proc. Natl. Acad. Sci. U. S. A. 99:17173-17178.

23. Suganuma, R., et al. 2005. Alkylated imino sugars, reversible male infertility-inducing agents, do not affect the genetic integrity of male mouse germ cells during short-term treatment despite induction of sperm deformities. Biol. Reprod. 72:805-813.

24. Walden, C.M., Butters, T.D., Dwek, R.A., Platt, F.M., and van der Spoel, A.C. 2006. Long-term non-hormonal male contraception in mice using N-butyldeoxynojirimycin. Hum. Reprod. 21:1309-1315.

25. Elbein, A.D. 1987. Inhibitors of the biosynthesis and processing of $\mathrm{N}$-linked oligosaccharide chains. Annu. Rev. Biochem. 56:497-534.

26. Tifft, C.J., and Proia, R.L. 2000. Stemming the tide: glycosphingolipid synthesis inhibitors as therapy for storage diseases. Glycobiology. 10:1249-1258.

27. Bodennec, J., Pelled, D., and Futerman, A.H. 2003. Aminopropyl solid phase extraction and 2 D TLC of neutral glycosphingolipids and neutral lysoglycosphingolipids. J. Lipid Res. 44:218-226.

28. Sandhoff, R, et al. 2005. Novel class of glycosphingolipids involved in male fertility. J. Biol. Chem. 280:27310-27318.

29. Dinur, T., Grabowski, G.A., Desnick, R.J., and Gatt, S. 1984. Synthesis of a fluorescent derivative of glucosyl ceramide for the sensitive determination of glucocerebrosidase activity. Anal. Biochem. 136:223-234.

30. Van Weely, S., Brandsma, M., Strijland, A., Tager, J.M., and Aerts, J.M.F.G. 1993. Demonstration of the existence of a second, non-lysosomal glucocerebrosidase that is not deficient in Gaucher disease. Biochim. Biophys. Acta. 1181:55-62.
31. Overkleeft, H.S., et al. 1998. Generation of specific deoxynorjirimycin-type inhibitors of the non-lysosomal glucosylceramidase. J. Biol. Chem. 273:26522-26527.

32. Pentchev, P.G., Brady, R.O., Hibbert, S.R., Gal, A.E., and Shapiro, D. 1973. Isolation and characterization of glucocerebrosidase from human placental tissue. J. Biol. Chem. 248:5256-5261.

33. Xu, Y.-H., Quinn, B., Witte, D., and Grabowski, G.A 2003. Viable mouse models of acid -glucosidase deficiency. Am. J. Pathol. 163:2093-2101.

34. Beutler, E. 1997. Enzyme replacement therapy for Gaucher's disease. Baillieres Clin. Haematol. 10:751-763.

35. Brugh, V.M., 3rd, Maduro, M.R., and Lamb, D.J. 2003. Genetic disorders and infertility. Urol. Clin. North Am. 30:143-152.

36. Xu, X., Toselli, P.A., Russell, L.D., and Seldin, D.C. 1999. Globozoospermia in mice lacking the casein kinase II $\alpha^{\prime}$ catalytic subunit. Nat. Genet. 23:118-121

37. Yao, R., et al. 2002. Lack of acrosome formation in mice lacking a Golgi protein, GOPC. Proc. Natl. Acad. Sci. U. S. A. 99:11211-11216

38. Kilani, Z., et al. 2004. Evaluation and treatment of familial globozoospermia in five brothers. Fertil. Steril. 82:1436-1439.

39. Martin, R.H., Greene, C., and Rademaker, A.W. 2003. Sperm chromosome aneuploidy analysis in a man with globozoospermia. Fertil. Steril. 79:1662-1664.

40. Schmiady, H., Schulze, W., Scheiber, I., and Pfuller, B. 2005. High rate of premature chromosome condensation in human oocytes following microinjection with round-headed sperm: case report. Hum. Reprod. 20:1319-1323.

41. Pirrello, O., et al. 2005. Search for mutations involved in globozoospermia. Hum. Reprod. 20:1314-1318.

42. Mansour, S.L., Thomas, K.R., and Capecchi, M.R. 1988. Disruption of the proto-oncogene int- 2 in mouse embryo-derived stem cells: a general strategy for targeting mutations to non-selectable genes. Nature. 336:348-352.

43. Lund, E.G., et al. 2003. Knockout of the cholesterol 24-hydroxylase gene in mice reveals a brain-specific mechanism of cholesterol turnover. J. Biol. Chem. 278:22980-22988.

44. Turley, S.D., Herndon, M.W., and Dietschy, J.M. 1994. Reevaluation and application of the dualisotope plasma ratio method for the measurement of intestinal cholesterol absorption in hamsters. J. Lipid Res. 35:328-339.

45. Schwarz, M., Russell, D.W., Dietschy, J.M., and Turley, S.D. 1998. Marked reduction in bile acid synthesis in cholesterol $7 \alpha$-hydroxylase-deficient mice does not lead to diminished tissue cholesterol turnover or to hypercholesterolemia. J. Lipid Res. 39:1833-1843.

46. Cheng, J.B., and Russell, D.W. 2004. Mammalian wax biosynthesis. I. Identification of two mammalian fatty acyl-coenzyme A reductases with different substrate specificities and tissue distributions. J. Biol. Chem. 279:37789-37797.

47. Howlett, S.K., and Bolton, V.N. 1985. Sequence and regulation of morphological and molecular events during the first cell cycle of mouse embryogenesis. J. Embryol. Exp. Morphol. 87:175-206.

48. Merrill, A.H.J., Sullards, M.C., Allegood, J.C., Kelly, S., and Wang, E. 2005. Sphingolipidomics: highthroughput, structure-specific, and quantitative analysis of sphingolipids by liquid chromatography tandem mass spectrometry. Methods. 36:207-224. 